\title{
A Study on Power Flow Control for Distributed Generator with EDLC
}

\author{
Shin-ichi Hamasaki*, Mineo Tsuji*, and Eiji Yamada* \\ * Department of Electrical and Electronic Engineering, Nagasaki University, 1-14 Bunkyo-machi, \\ Nagasaki, 852-8521, E-mail: hama-s@nagasaki-u.ac.jp, (Japan)
}

\begin{abstract}
Power flow control for the distributed generator (DG) with Electric Double Layer Capacitor (EDLC) is studied. The DG system consists of a voltage type inverter for connection to the AC-line and a two-quadrant DC chopper for connection to the DC-bus. The inverter and the DC chopper can be controlled cooperatively to regulate active power flow. The active power from $\mathrm{DG}$ to $\mathrm{AC}$ line is regulated by the control method. And considering the power flow in DC-bus, the EDLC current is regulated to obtain proper balance of the power and DC-bus voltage by the control method. The control theory and considerations of effectiveness of the proposed control method in simulation are presented.
\end{abstract}

Index Terms-- distributed generator, EDLC, power leveling

\section{INTRODUCTION}

Distributed generators (DG) using a wind turbine generation and solar-cell generation are very attracted as a countermeasure of energy. The DG is required to connect to power line and work stably not to occur a voltage drop. On the other hand, the generation systems such as the solar-cell and the wind turbine have essential problem of the unevenness of the power generation. Thus power storage devices such as a battery, a flywheel and others are connected together for power leveling in the DG system. The Electric Double Layer Capacitor (EDLC) is one of expected devices and applied for storage system of the energy.

In this paper, a power flow control method of the DG system with EDLC is investigated. The DG system consists of a voltage type inverter and a two-quadrant DC chopper for connection to the AC-line and the DC-bus respectively. In this method, the active power and the reactive power is controlled independently. The inverter and the DC chopper can be controlled cooperatively to regulate active power flow and the DC-bus voltage. The active power from the generator can flow to the power line for power supply and to the EDLC for power charge voluntary. And a power line flow control, which is able to achieve power supply from the DG independently without the power line, is proposed.

Theory of the proposed control method and simulation results for typical cases is described.

\section{Control Method}

\section{A. Circuit for analysis}

Fig.1 shows a circuit for analysis. The distributed gene-

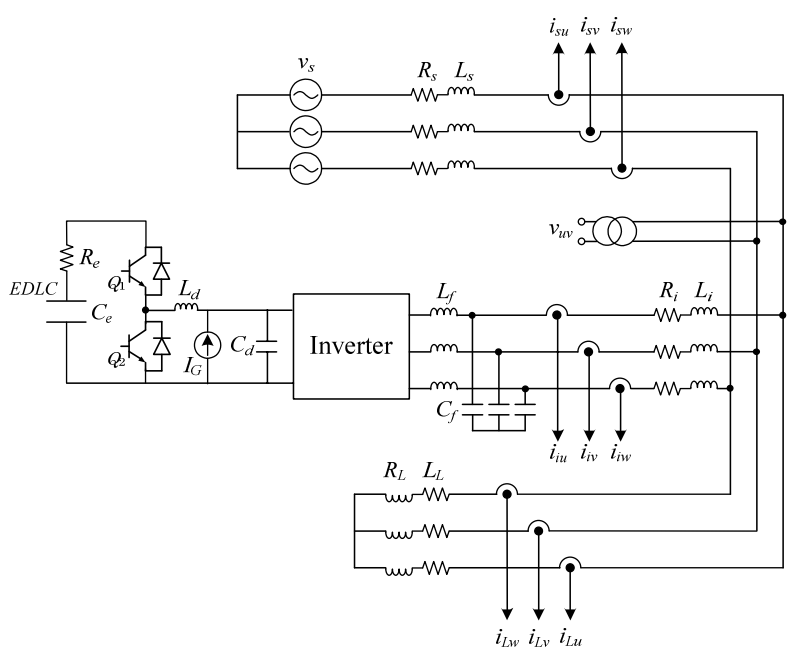

Fig. 1. Circuit for analysis.

rator (DG) is connected parallel between the power line $\left(v_{s}, L_{s}, R_{s}\right)$ and the load $\left(L_{L}, R_{L}\right)$. The DG consists of a voltage type inverter and a two-quadrant DC chopper connected to the EDLC. $I_{G}$ is current of generator such as a photovoltaic system.

\section{B. Control method of AC side power}

The detected three-phase current and voltage are transformed to the $\mathrm{d}-\mathrm{q}$ axis value by the $\mathrm{d}-\mathrm{q}$ transform de scribed in (1).

$$
\left[\begin{array}{l}
i_{d} \\
i_{q}
\end{array}\right]=\sqrt{\frac{2}{3}}\left[\begin{array}{ccc}
\sin \theta & \sin \left(\theta-\frac{2}{3} \pi\right) & \sin \left(\theta+\frac{2}{3} \pi\right) \\
\cos \theta & \cos \left(\theta-\frac{2}{3} \pi\right) & \cos \left(\theta+\frac{2}{3} \pi\right)
\end{array}\right]\left[\begin{array}{l}
i_{u} \\
i_{v} \\
i_{w}
\end{array}\right]
$$

Fig.2 shows the definitions of the d-q axis and $\theta$.
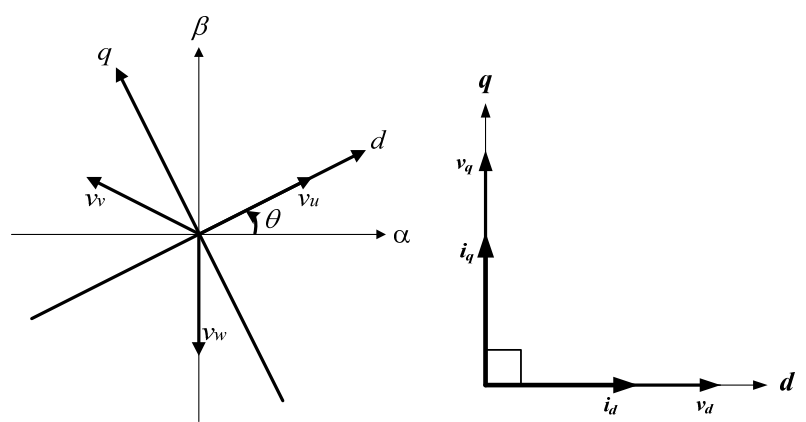

Fig. 2. Definition of d-d axis and $\theta$. 
$\theta$ is given as a phase of u-phase line voltage $v_{u}$ and calculated from the phase $\theta_{u v}$ of line-to-line voltage $v_{u v}$ by (2).

$$
\theta=\theta_{u}=\theta_{u v}-\frac{\pi}{6}
$$

Here the line voltages are defined as (3)-(5).

$$
\begin{aligned}
& v_{u}=\sqrt{\frac{2}{3}} V \sin \theta \\
& v_{v}=\sqrt{\frac{2}{3}} V \sin \left(\theta-\frac{2}{3} \pi\right) \\
& v_{w}=\sqrt{\frac{2}{3}} V \sin \left(\theta+\frac{2}{3} \pi\right)
\end{aligned}
$$

Then voltages $v_{d}$ and $v_{q}$ are calculated by (1).

$$
\begin{aligned}
& v_{d}=V \\
& v_{q}=0
\end{aligned}
$$

The active power $P$ and the reactive power $Q$ is obtained in Fig.2.

$$
\begin{aligned}
& P=v_{d} i_{d}+v_{q} i_{q} \\
& Q=v_{d} i_{q}-v_{q} i_{d}
\end{aligned}
$$

By (6) and (7), (8) and (9) becomes as (10) and (11).

$$
\begin{aligned}
& P=V i_{d} \\
& Q=V i_{q}
\end{aligned}
$$

(10) and (11) means that the active power $P$ and the reactive power $Q$ is depend on $i_{d}$ and $i_{q}$ respectively. Thus $i_{d}$ is called an active current and $i_{q}$ is called an reactive current.

Fig.3 illustrates a block diagram of the active and the reactive power control of the $\mathrm{DG}$.

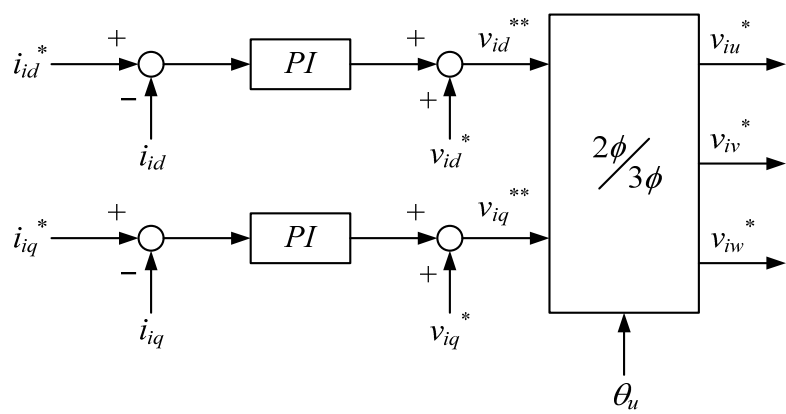

Fig. 3. Block diagram of the power control of the DG.

The control law becomes (12) and (13).

$$
\begin{aligned}
& v_{i d}^{* *}=v_{i d}^{*}+K_{p d}\left(i_{i d}^{*}-i_{i d}\right)+K_{i d} \int_{0}^{t}\left(i_{i d}^{*}-i_{i d}\right) d t \\
& v_{i q}^{* *}=v_{i q}^{*}+K_{p q}\left(i_{i q}^{*}-i_{i q}\right)+K_{i q} \int_{0}^{t}\left(i_{i q}^{*}-i_{i q}\right) d t
\end{aligned}
$$

$i_{i d}$ and $i_{i q}$ are the active and the reactive current of the detected output AC current of the DG respectively. $v_{i d}{ }^{*}$ and $v_{i q}{ }^{*}$ are criterion reference voltages and given as $v_{i d}{ }^{*}=$ $V$ and $v_{i q}{ }^{*}=0 . i_{i d}{ }^{*}$ and $i_{i q}{ }^{*}$ are the current reference, which are determined in compliance with generated condition and load usage condition.

The determination of the reference has three modes.

1. Synchronous mode - When $i_{i d}{ }^{*}=0$ and $i_{i q}{ }^{*}=0$ are given, the DG becomes synchronous voltage to the line voltage.

2. Power supply mode - When $i_{i d}{ }^{*}>0$ are given, the DG supplies the active power to the $\mathrm{AC}$ line. $i_{i q}{ }^{*}$ can be determined optionally.

3. Power charge mode - When $i_{i d}{ }^{*}<0$ are given, the DG can receive the active power to the DC line for the EDLC charge. $i_{i q}{ }^{*}$ can be determined optionally.

\section{Control method of DC side power}

Fig.4 shows the relationship of the power flow in the DG. All the power flow must be balanced properly.

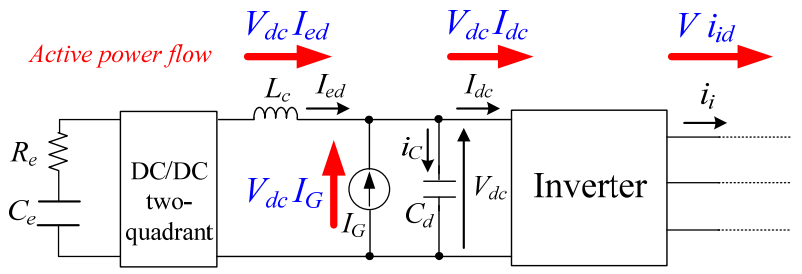

Fig. 4. Power flow of the DC side.

The active power $P$ of the DG satisfies

$$
P=V i_{i d}=V_{d c} I_{d c}
$$

Further power flow balance satisfies (15).

$$
V_{d c} I_{e d}+V_{d c} I_{G}-V_{d c} i_{C}=V_{d c} I_{d c}
$$

Thus,

$$
I_{e d}=I_{d c}+i_{C}-I_{G} \text {. }
$$

Control of the two-quadrant DC chopper with DC-bus voltage control is given as Fig.5.

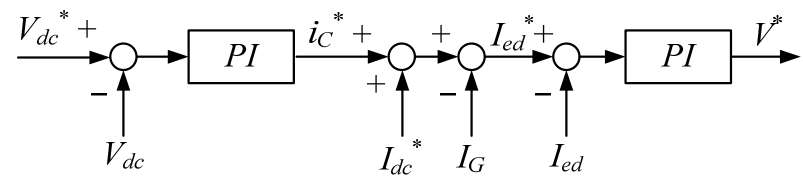

Fig. 5. Block diagram of the DC bus voltage and EDLC current control.

DC-link voltage $V_{d c}$ and the EDLC output current are regulated by the PI control.

$$
\begin{aligned}
& I_{C}^{*}=K_{p d c}\left(V_{d c}^{*}-V_{d c}\right)+K_{i d c} \int_{0}^{t}\left(V_{d c}^{*}-V_{d c}\right) d t \\
& V^{*}=K_{p e d}\left(I_{c d}^{*}+I_{d c}^{*}-I_{e d}\right)+K_{i e d} \int_{0}^{t}\left(I_{c d}^{*}+I_{d c}^{*}-I_{e d}\right) d t
\end{aligned}
$$

A DC current reference $I_{d c}{ }^{*}$ of the inverter can be obtained by (14).

$$
I_{d c}^{*}=\frac{V i_{i d}^{*}}{V_{d c}}
$$

When the EDLC supplies the power, the DC chopper 
works as a back converter by PWM control of $Q_{1}$ in Fig.1. When the EDLC is charged the power, the DC chopper works as a boost converter by PWM control of $Q_{2}$.

When the generator is active $\left(I_{G}>0\right)$, several patterns of the active power flow are considered.

1. The active power is supplied from the generator to the load without the EDLC power.

$$
\left(I_{G}>0, I_{d c}>0, I_{e d}=0\right)
$$

2. The active power is supplied from the generator and the EDLC to the load. In this case, the EDLC compensates the power shortage of the generator.

$$
\left(I_{G}>0, I_{d c}>0, I_{e d}>0\right)
$$

3. The active power is supplied from the generator to the EDLC without the load power supply.

$$
\left(I_{G}>0, I_{d c}=0, I_{e d}<0\right)
$$

4. The active power is supplied from the generator to the EDLC and the load.

$$
\left(I_{G}>0, I_{d c}>0, I_{e d}<0\right)
$$

\section{Power flow with the line power control}

A power line flow control is introduced. It is able to achieve power supply without an active power flow from the power line. Thus the control can be realized the active power flow from the DG independently with the power leveling.

The reference of the active power of the inverter is determined by (20). And relation between the AC-bus currents satisfies (21).

$$
\begin{aligned}
& i_{i d}^{*}=i_{i d}+i_{S d} . \\
& i_{L d}=i_{i d}+i_{S d} .
\end{aligned}
$$

The active current $i_{i d}$ of the DG becomes the same as the active current $i_{L d}$ of the load at steady state.

\section{SiMULATIONS}

Simulation is executed to verify the proposed control method by using the circuit in Fig.1. Parameters of the circuit are shown in Table 1.

The current reference of DG is selected as $i_{i d}{ }^{*}=k i_{L d}$, $i_{i q}{ }^{*}=k i_{L q}$. The constant $k$ determines a rate of the power share between the DG and the power line. Here, $k=0.5$ is set in the simulation. The reference of DC-bus voltage is set to $200 \mathrm{~V}$. The DG starts to work at $t=0.1 \mathrm{~s}$ in the simulation. Typical 5 cases are expressed in this paper.

TABLE I

PARAMETERS TABLE OF THE SIMULATION

\begin{tabular}{|c|c|c|c|}
\hline$V(\mathrm{RMS})$ & $100[\mathrm{~V}]$ & Frequency & $60[\mathrm{~Hz}]$ \\
\hline$R_{S}$ & $0.75[\Omega]$ & $L_{S}$ & $500[\mu \mathrm{H}]$ \\
\hline$R_{i}$ & $0.45[\Omega]$ & $L_{i}$ & $300[\mu \mathrm{H}]$ \\
\hline$R_{L}$ & $15.0[\Omega]$ & $L_{L}$ & $10.0[\mathrm{mH}]$ \\
\hline$C_{d}$ & $5000[\mu \mathrm{F}]$ & $C_{e}$ & $1.0[\mathrm{~F}]$ \\
\hline$R_{e}$ & $0.2[\Omega]$ & $L_{c}$ & $4.0[\mathrm{mH}]$ \\
\hline
\end{tabular}

\section{A. Power supply from $\operatorname{EDLC}\left(I_{G}=0\right)$}

In first case, the generator current is set to 0 . Thus only the EDLC supplies the active power. Simulation results in this case are shown in Figs.6-13. Figs.6-8 show phase currents of AC side respectively. Figs. 9 and 10 show the active and reactive currents of AC side respectively. Fig. 11 shows the currents of DC-bus, Fig.12 sows the DC-bus voltage and Fig. 13 shows the EDLC voltage.

The active power and the reactive power to the load can be shared by half of the DG and half of the power line on the $\mathrm{AC}$ side in Figs.6-10. Output current of the EDLC and DC-link current of the inverter is balanced on the DC-bus in Fig.11. The DC-bus voltage $V_{d c}$ can be regulated to $200 \mathrm{~V}$ in Fig. 12. The EDLC voltage $V_{e d}$ reduces for power supply in Fig.13.

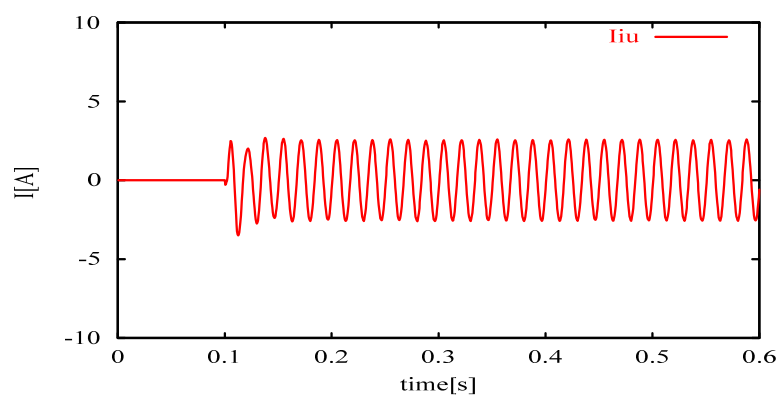

Fig. 6. Phase current $i_{i u}$ of the DG.

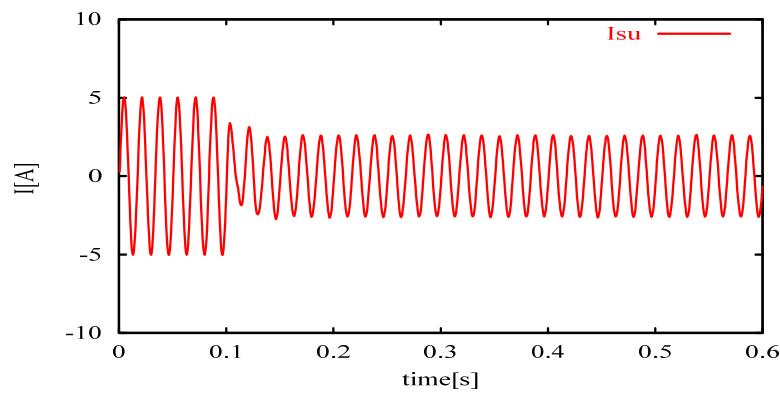

Fig. 7. Phase current $i_{s u}$ of the power line.

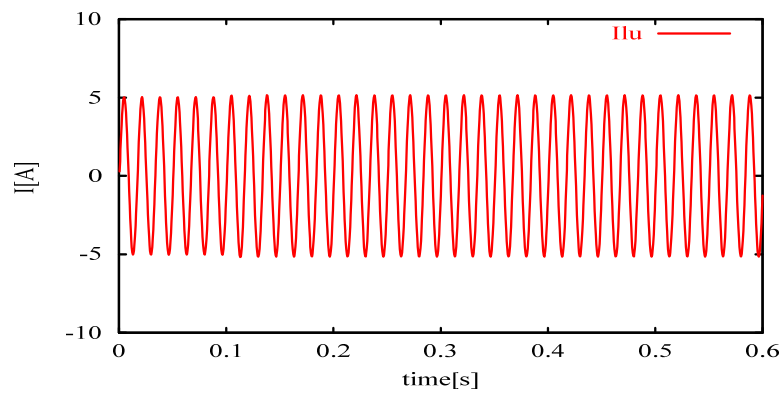

Fig. 8. Phase current $i_{L u}$ of the load.

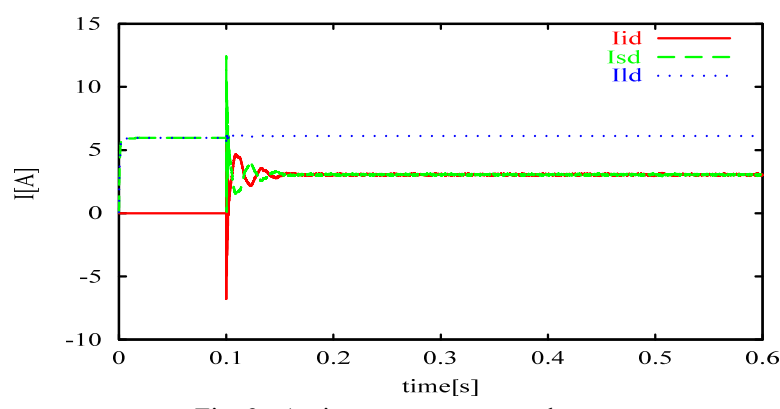

Fig. 9. Avtive current $i_{i d}, i_{s d}$ and $i_{L d}$. 


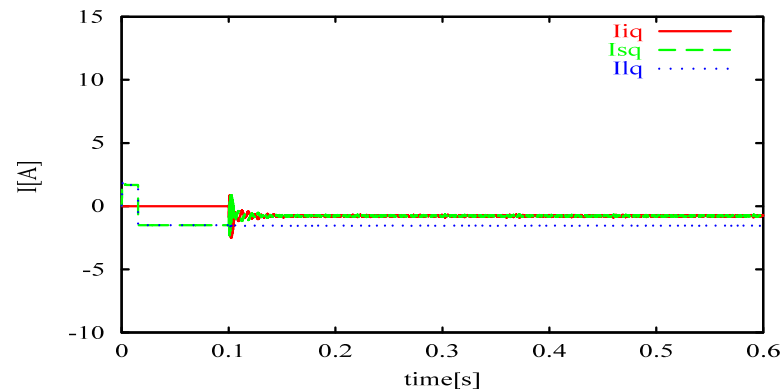

Fig. 10. Reactive current $i_{i q}, i_{s q}$ and $i_{L q}$.

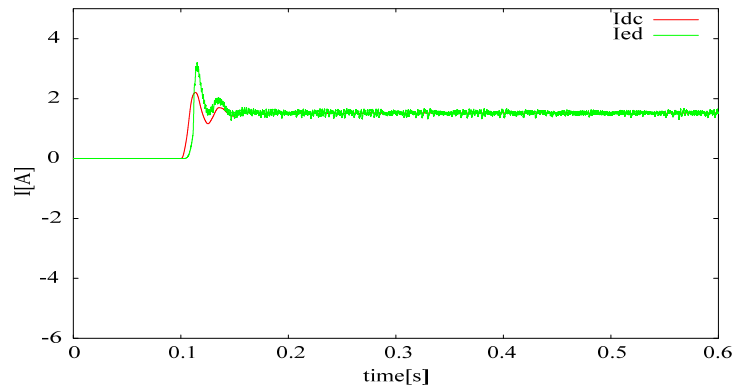

Fig. 11. EDLC output current $I_{e d}$ and DC-bus current $I_{d c}$

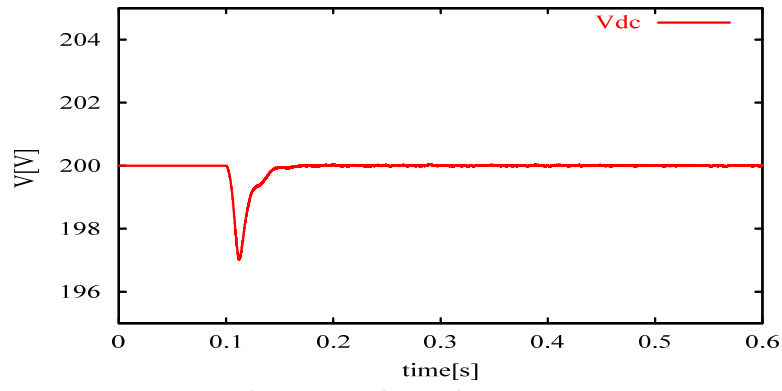

Fig. 12. DC-bus voltage $V_{d c}$.

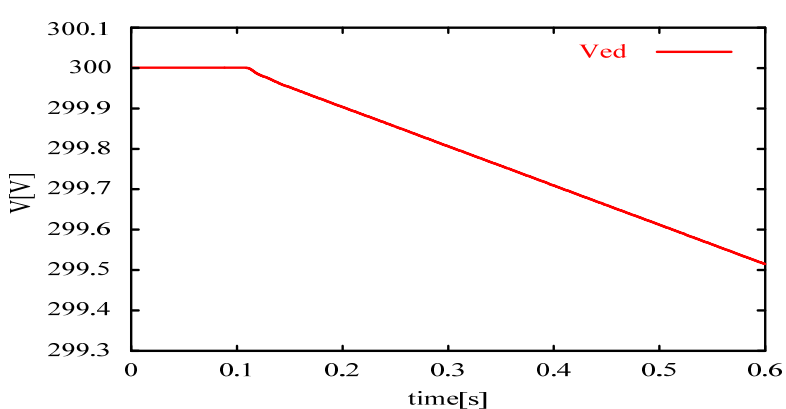

Fig. 13. EDLC voltage $V_{e d}$

\section{B. Power charge to EDLC from power line $\left(I_{G}=0\right)$}

When the power is charged from the power line to the EDLC, simulation results are shown in 14-18. In this situation, $i_{i d}{ }^{*}=-6 \mathrm{~A}$ and $i_{i q}{ }^{*}=0 \mathrm{~A}$ is selected. Figs. 14 and 15 show the active and reactive currents of $\mathrm{AC}$ side respectively. Fig.16 shows the currents of DC-bus, Fig.17 shows the DC-bus voltage and Fig. 18 shows the EDLC voltage. Each phase current is omitted in this case.

The power line supplies the active power to the DG and the load and the DG output current becomes negative for EDLC charge in Fig.14. Output currents of the EDLC and DC-link are balanced in Fig.16. The DC-bus voltage $V_{d c}$ can be regulated to $200 \mathrm{~V}$ in Fig. 17. The EDLC voltage $V_{e d}$ increases for power charge in Fig. 18.

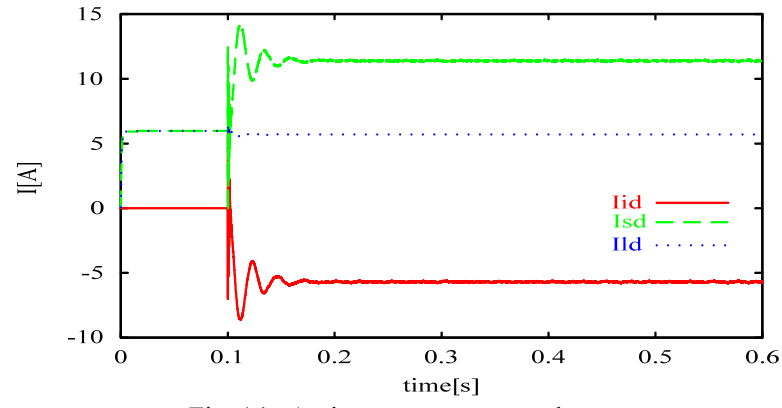

Fig. 14. Avtive current $i_{i d}, i_{s d}$ and $i_{L d}$.

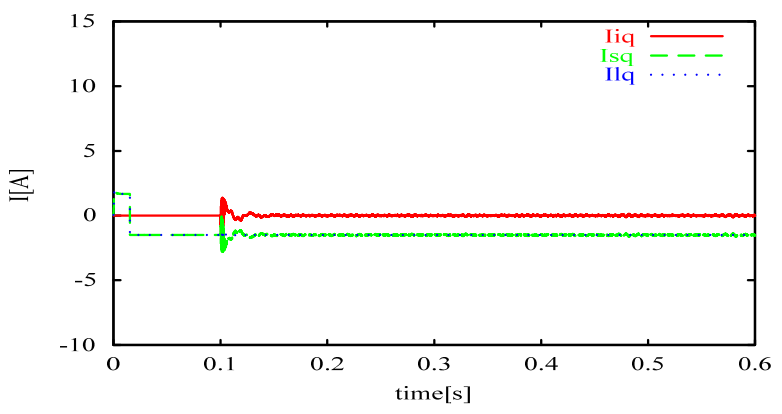

Fig. 15. Reactive current $i_{i q}, i_{s q}$ and $i_{L q}$.

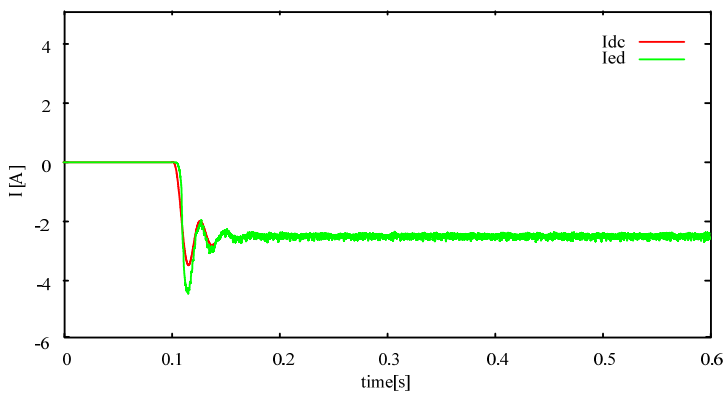

Fig. 16. EDLC output current $I_{e d}$ and DC-bus current $I_{d c}$

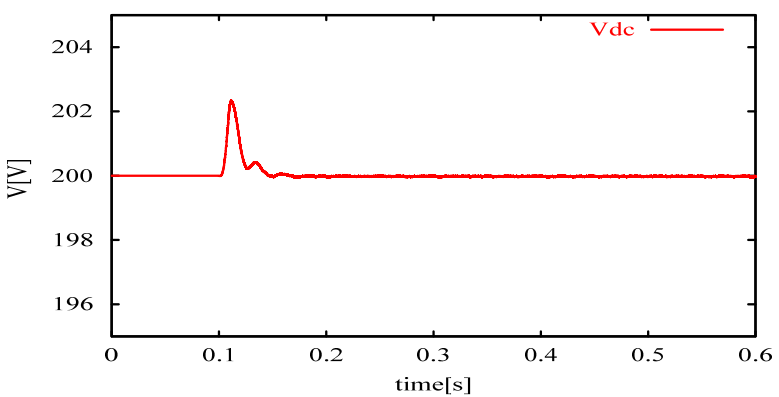

Fig. 17. DC-bus voltage $V_{d c}$.

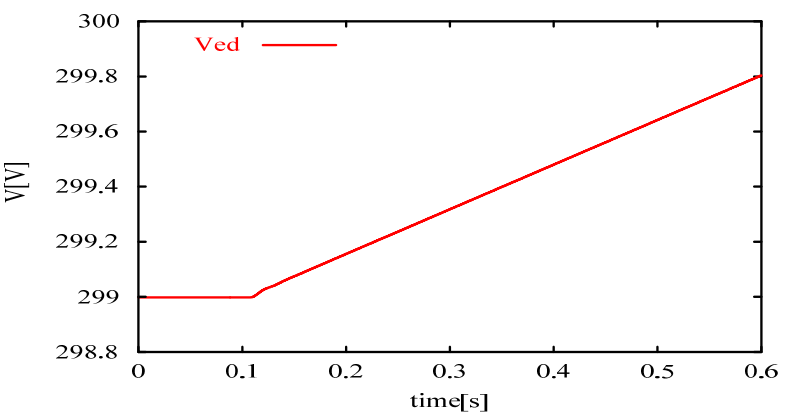

Fig. 18. EDLC voltage $V_{e d}$. 


\section{Power supply from generator}

When the power is supplied from the generator to the load, simulation results are shown in 19-22. In this situation, $i_{i d}{ }^{*}$ is calculated so as to satisfy $I_{d c}=I_{G}$ by (19). Output current of the generator is set to 10A. After $t=$ $1.0 \mathrm{~s}$, the load changes twice in this simulation.

Fig.19 shows the active currents of AC side. Fig.20 shows the currents of DC-bus. Figs. 21 and 22 show the DC-bus and the EDLC voltage respectively. Each phase current and reactive currents are omitted in this case.

In Fig.19, the active power from the DG flows to the load and power line until $t=1.0 \mathrm{~s}$, after $t=1.0 \mathrm{~s}$ the active power the DG and the power line flow to the load. Thus the active power from the DG becomes constant and $I_{d c}$ and $I_{G}$ are balanced in Fig.20. The DC-bus voltage $V_{d c}$ can be regulated to $200 \mathrm{~V}$ in Fig.21. The EDLC voltage $V_{e d}$ keeps constant at steady state in Fig.22, because output current of the EDLC is $0 \mathrm{~A}$.

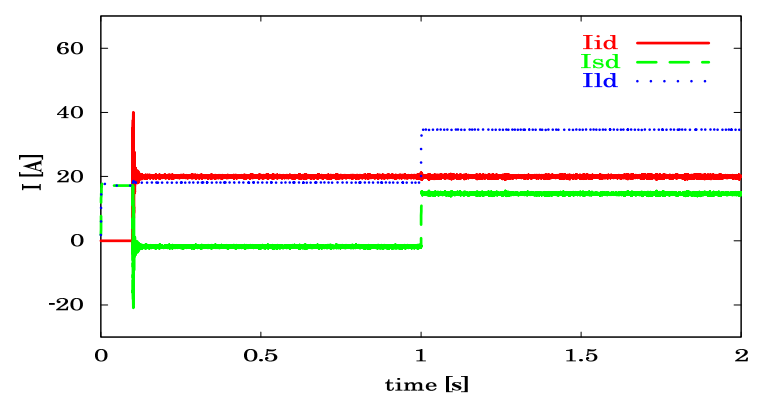

Fig. 19. Avtive current $i_{i d}, i_{s d}$ and $i_{L d .}$

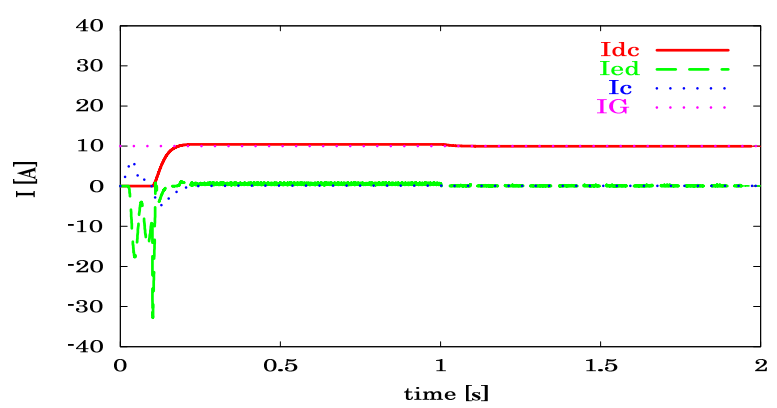

Fig. 20. DC-bus current $I_{d c}, \mathrm{I}_{e d}, \mathrm{I}_{C}$ and $I_{G}$.

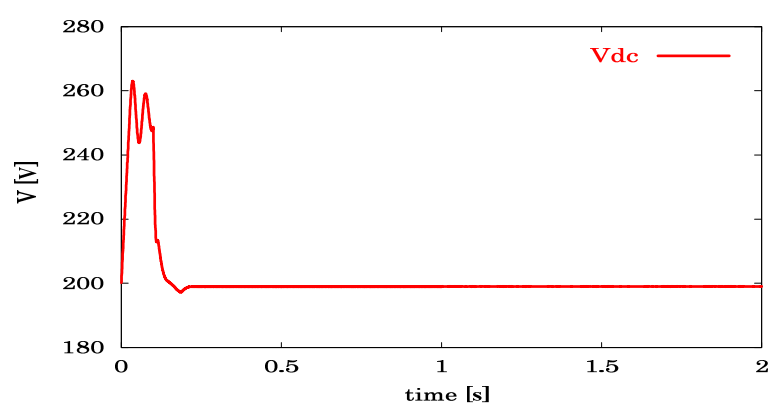

Fig. 21. DC-bus voltage $V_{d c}$.

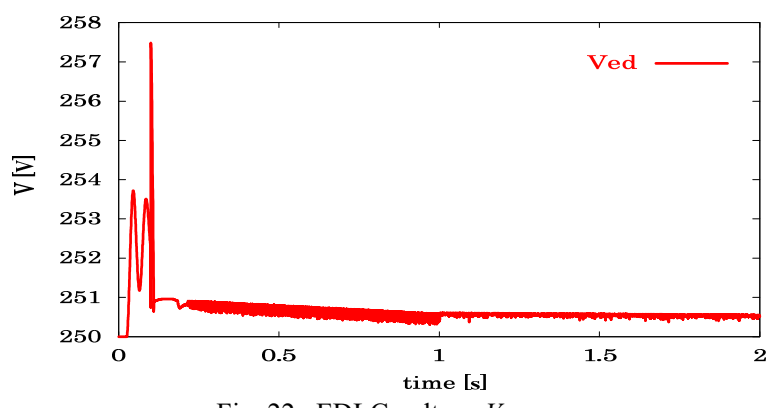

Fig. 22. EDLC voltage $V_{e d}$.

\section{Power charge to EDLC from generator}

When the power is supplied from the generator to the EDLC, simulation results are shown in 23-26. In this situation, $i_{i d}{ }^{*}$ is calculated so as to satisfy $I_{d c}=0$. Output current of the generator is set to $5 \mathrm{~A}$. After $t=1.0 \mathrm{~s}$, the load changes twice in this simulation.

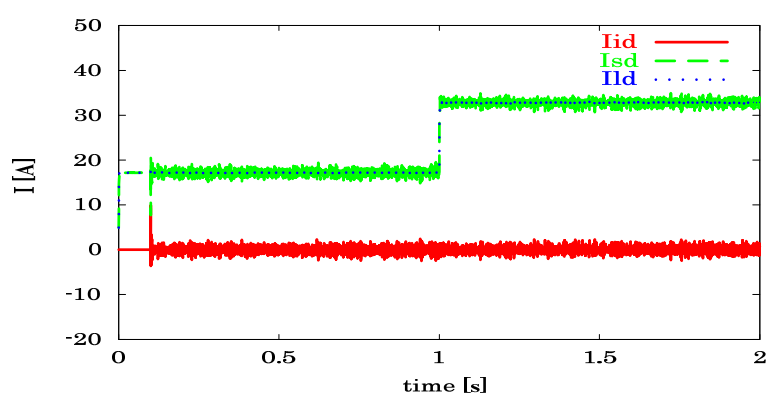

Fig. 23. Avtive current $i_{i d}, i_{s d}$ and $i_{L d}$.

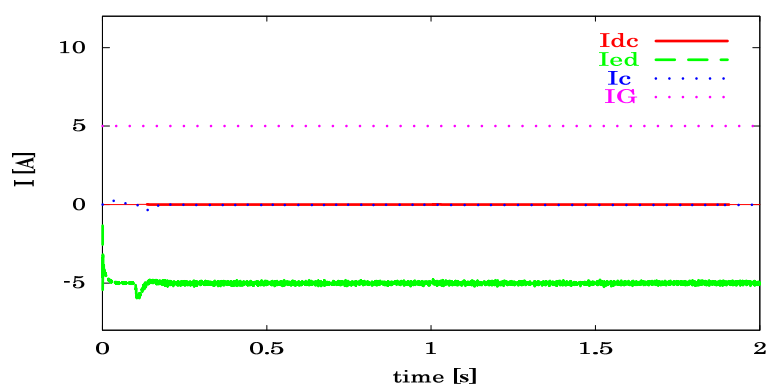

Fig. 24. DC-bus current $I_{d c}, \mathrm{I}_{e d}, \mathrm{I}_{C}$ and $I_{G}$.

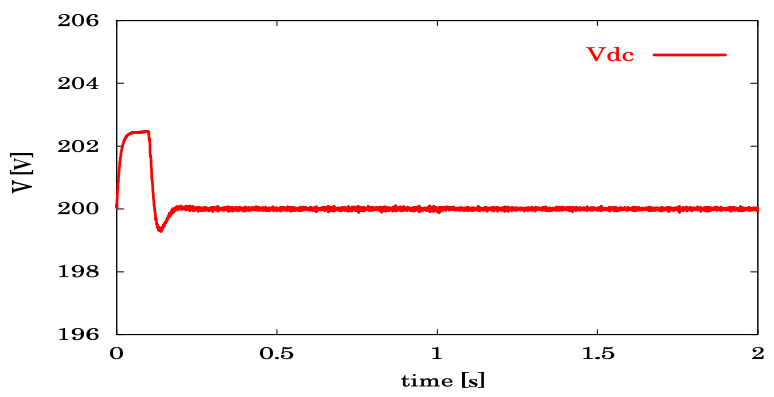

Fig. 25. DC-bus voltage $V_{d c}$. 


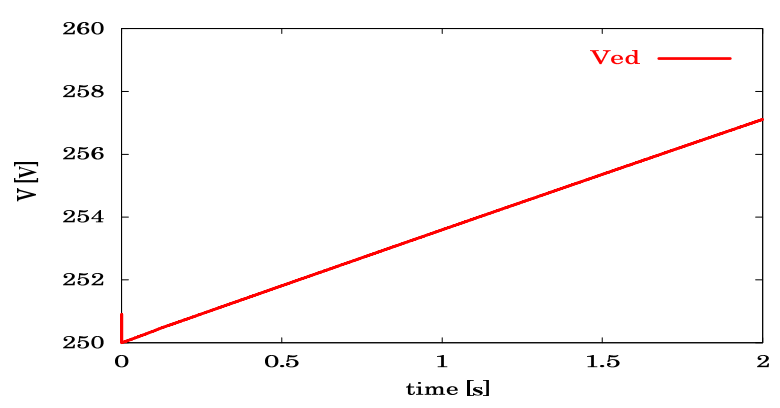

Fig. 26. EDLC voltage $V_{e d}$.

Fig.23 shows the active currents of AC side. Fig.24 shows the currents of DC-bus. Figs. 25 and 26 show the DC-bus and the EDLC voltage respectively. Each phase current and reactive currents are omitted in this case.

In Fig.23, All the active power of the load is provided from the power line, because the DG output current is regulated to 0 . Thus $I_{d c}$ becomes 0 and all the generated power of the generator flows to the EDLC for charge in Fig.24. The DC-bus voltage $V_{d c}$ can be regulated to $200 \mathrm{~V}$ in Fig.25. The EDLC voltage $V_{e d}$ increases for power charge in Fig.26.

\section{E. Power charge with the line power control}

When the line power control is applied, simulation results are shown in 27-30. In this case, $i_{i d}{ }^{*}$ is determined by (20). Output current of the generator is set to 15A. After $t=3.5 \mathrm{~s}$, the load changes twice in this simulation. Fig.27 shows the active currents of AC side. Fig.28 shows the currents of DC-bus. Figs. 29 and 30 show the DC-bus and the EDLC voltage respectively.

In Fig.27, all the active power of the load is always provided from the DG and the power line current becomes 0. In Fig.28, the power from the generator provides all the DG output for $I_{G}>I_{d c}$ and excess power of the generator flows to the EDLC until $t=3.5 \mathrm{~s}$. After $t$ $=3.5 \mathrm{~s}$, All the power from the generator flows to the load for $I_{G}<I_{d c}$ and the power of the EDLC automatically flows to the load for power shortage compensation.

The DC-bus voltage $V_{d c}$ can be regulated to $200 \mathrm{~V}$ at steady state after slightness fluctuation in Fig.29. The EDLC voltage $V_{e d}$ increases for power charge until $t=$ $3.5 \mathrm{~s}$ and decreases for power supply after that in Fig.30.

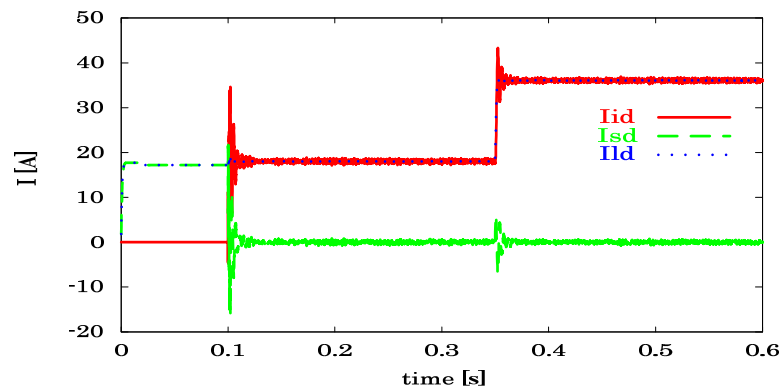

Fig. 27. Avtive current $i_{i d}, i_{s d}$ and $i_{L d}$.

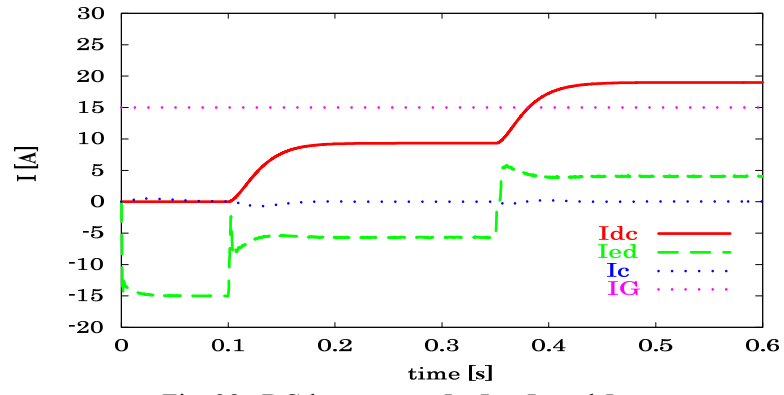

Fig. 28. DC-bus current $I_{d c}, \mathrm{I}_{e d}, \mathrm{I}_{C}$ and $I_{G}$.

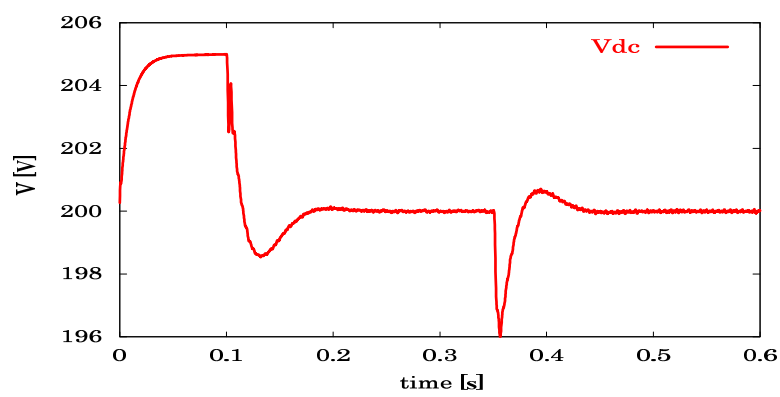

Fig. 29. DC-bus voltage $V_{d c}$.

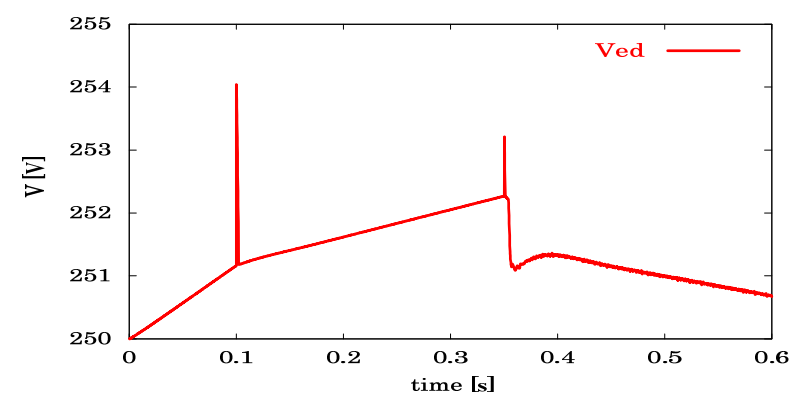

Fig. 30. EDLC voltage $V_{\text {ed }}$.

\section{CONCLUSIONS}

Power flow control for the distributed generator (DG) with EDLC is studied and the line power control is introduced. The active power and the reactive power from DG to AC line can be regulated by the control method independently. And considering the power flow in DC side, the EDLC current is regulated by the control method to obtain proper balance of the power and DC-bus voltage. The line power control can provide all the power to the load by the DG without the power supply from the power line.

The control theory of the control method is described and simulations of typical cases verified effectiveness of the proposed control method.

\section{REFERENCES}

[1] Y. Ito, Z. Yang, H. Akagi : A Control Method of a Small-Scale DC Power System Including Distributed Generators (in Japanese), JIEE Trans. Industrial Application, vol. 126, No. 9,2006, pp.12361242.

[2] Y. Ito, H. Akagi, Z. Yang : Consideration from Viewpoint of Output Impedance Concerning Control Method for Parallel Operation of CVCF Inverters (in Japanese), JIEE Trans. Industrial Application, vol. 128, No. 2, 2008, pp.102-109.

[3] H. Kakigano, T. Ise, et al. : DC Voltage Control of the DC MicroGrid for Super High Quality Electric Power Distribution (in Japanese), JIEE Trans. Industrial Application, vol. 127, No. 8, 2007, pp.890-897. 